\title{
A Randomised Controlled Trial to evaluate the effect of a new skin care regimen on skin barrier function in those with podoconiosis in Ethiopia.
}

Brooks, $\mathrm{J}^{1}$.; Ersser, S.J ${ }^{2}$; Cowdell, $\mathrm{F}^{3}$; Gardiner, $\mathrm{E}^{1}$.; Mengistu, $\mathrm{A}^{4}$., Matts P.J ${ }^{5}$.

1. University of Hull, UK; 2. University of York, UK; 3. Birmingham City University, UK: 4. Sodo, Ethiopia ; 5. Procter and Gamble, Greater London Innovation Centre, Egham, UK.

Corresponding author: E mail: jb284@btinternet.com

\section{Funding sources}

Procter and Gamble (yet fully independent work) sponsored PhD studentship.

\section{Conflict of interest statement}

There were no conflicts of interest.

\section{What is known about topic:}

- Podoconiosis (non-filarial elephantiasis) is a tropical skin disease sometimes known as "Mossy Foot" due to moss-like skin eruptions. It is caused by irritant soil particulates and pathogens entering the plantar skin via skin breaches affecting the lower leg lymphatics. It is not curable but is treatable.

- The current podoconiosis skin care treatment regimen reduces clinical disease stage and oedema, improves skin condition and quality of life but may not be optimum and requires 6 litres of scarce water resource.

\section{What does this add:}

- This is the first published RCT evaluating podoconiosis skin treatment regimens using quantitative measures of skin barrier function (SBF).

- A new treatment regimen, incorporating $2 \%$ glycerine $(\mathrm{v} / \mathrm{v})$ in $1 / 6$ of the current water volume, significantly improved SBF and clinical disease presentation compared to the current regimen. 


\begin{abstract}
Background

Podoconiosis affects an estimated 3 million people in Ethiopia with a further 19 million at risk. Volcanic soil and pathogens enter skin breaches in the feet causing inflammation, lymphoedema and hyperkeratosis. There is no robust evidence on optimal podoconiosis skin care regimens to improve SBF.
\end{abstract}

\title{
Objectives
}

To evaluate the effectiveness of a new, low-cost, evidence-based intervention to improve $\mathrm{SBF}$ in the lower limbs of those with podoconiosis.

\section{Methods}

A randomized control trial (RCT) was conducted over 3 months in two podoconiosis clinics $(\mathrm{n}=193)$. The intervention comprised $2 \%$ glycerine $(\mathrm{v} / \mathrm{v})$ added to a reduced amount of soaking water. The control group received the current skin care regimen. Primary outcome measures were trans-epidermal water loss (TEWL) and stratum corneum hydration (SCH) at four specific sites on the lower limbs.

\section{Results}

Improvement in SBF was observed in both groups across all measurement sites and time points, although this was significantly greater in the experimental group. TEWL reduced in both groups at all sites. For example, on top of the foot the estimated group difference in TEWL at the fourth visit was $1.751(\mathrm{SE}=0.0390)$ in favour of the experimental group $(\mathrm{t}=3.154, \mathrm{df}=189.580, \mathrm{p}=0.002,95 \% \mathrm{CI}(0.0656$ to 2.846$))$, indicating a greater reduction in the experimental group. Similarly, at the same site the estimated group difference in $\mathrm{SCH}$ at the fourth visit was $-2.041(\mathrm{CI}=0.572)$ in favour of the experimental group $(\mathrm{t}=-3.565$, $\mathrm{df}=186.739, \mathrm{p}=<0.001), 95 \% \mathrm{CI}(-3.168$ to -0.911$))$, indicating a greater increase in the experimental group. There were also significantly greater reductions in odour, number of wounds and largest foot circumference in the experimental compared to the control group. 


\section{Conclusions}

The addition of $2 \%$ glycerine (v/v) to a reduced volume ( $83 \%$ reduction) of soaking water significantly improved SBF (Registered trial NCT02839772).

\section{Introduction}

Podoconiosis is a non-infectious skin disease resulting in bilateral and usually asymmetric lymphoedema below the knee ${ }^{1}$. It is found in over 20 countries across tropical Africa, Central America, and northern India ${ }^{2}$. Prevalence data is unavailable in most countries except in Ethiopia. The minerals smectite, mica and quartz (crystalline silica) within alkaline volcanic soil are associated with areas of prevalence ${ }^{3}$. Due to poverty or culture, subsistence farmers and others may not wear shoes or those providing inadequate protection. Plantar stratum corneum (SC) thickens, dries and becomes extremely brittle, leading to deep cracks and fissures allowing soil particles and bacteria to enter, triggering the inflammatory process ${ }^{4}$. Water is essential to cleanse the skin surface of soil and pathogens, to help maintain healthy SBF. This is a major challenge in the developing world, where water is typically carried to homes from remote stand pipes, wells or rivers. The use of this precious resource for washing skin is a relatively low priority, resulting in poor foot hygiene. Subsequent oedema disrupts superficial lymphatic drainage, causing further oedema and stress on deeper lymphatics. If overloaded, this secondary drainage system can fail, causing lymphoedematous feet and legs 5 . The high protein content of static lymph fluid in tissues leads to trophic skin changes, including hair loss, xerosis, hyperkeratosis, adipose tissue deposition and papillomatiasis ${ }^{6}$. Figure 1 proposes a cyclical pathogenic model for podoconiosis induction and propagation. Without therapeutic intervention, the cycle continues, with worsening lymphoedema and skin change. Disease progression has five stages of severity $(5=\text { most severe })^{7}$. Transforming growth factor beta 1 (TGF- $\beta 1$ ) has a pathogenic role in the disease and oxidative stress a lesser role ${ }^{8}$. The disease is thought to be T cell-mediated with high $(63 \%)$ hereditability ${ }^{9}$. Severe macro- and micro-economic effects are caused by significant social stigmatisation and episodic severe leg pain from adenolymphangitis (ADL $)^{10}$. Acute attacks of ADL cause leg inflammation and inguinal lymphadenopathy. This results in lost work days with subsequent loss of family income. The estimated cost in one region in Ethiopia (population of 1.5 million) was estimated at US\$ 16 million a year. Stigmatisation is widespread due to the appearance of the disease, unpleasant odour and the unfounded fear of infection. Patients report that they are unable to marry, are shunned by others and excluded from social events ${ }^{11}$. 
This ostracism increases as the disease progresses. Wearing shoes provides only partial protection. One large study found heel cracks and foot trauma present regardless of shoe type $^{12}$. Maintaining SBF health and effective washing of feet/legs is, therefore, essential in podoconiosis prevention.

The current treatment regimen taught in "Action on Podoconiosis and Integrated Development Organisation" (APIDO) clinics consists of washing feet/legs daily in soapy water, a 30 minute soak in 6 litres of water with $0.0125 \%(\mathrm{v} / \mathrm{v})$ sodium hypochlorite $(\mathrm{NaOCl})$, air drying and application of petrolatum jelly to augment SBF and reduce friction ${ }^{13}$. Surfactant action removes pathogens/soil, while the soak hydrates the SC (decreasing its elastic modulus, creating a pliable structure less likely to crack or split) and $\mathrm{NaOCl}$ reduces pathogen load. Whitfield's ointment is used, where appropriate, to treat fungal infection. A one year non-comparative longitudinal study using a similar regimen was effective in reducing disease clinical stage, oedema, and improving Quality of Life scores $(n=27)^{14}$. No previous RCTs assessing treatment regimens for this disease were identified.

We hypothesised that addition of low levels of humectant to the regimen would increase SC hygroscopicity improving SBF and, ultimately, clinical outcome. Glycerine was chosen because of its wide range of efficacy, low cost and availability even in resource-poor settings. In Ethiopia it can be obtained easily in road-side kiosks for around 50 pence/100ml). The glycerine concentration chosen $(2 \% \mathrm{v} / \mathrm{v})$ was based on a balance between cost and previous studies showing efficacy at this concentration ${ }^{15-18}$. Fluhr ${ }^{15}$ identified glycerine-related skin benefits as improved SCH, SBF, desmosomal degradation and skin mechanics, inhibition of SC lipid-phase transition, accelerated wound healing, reduced irritation and some antimicrobial efficacy. To conserve glycerine and water, we reduced the wash-water volume from 6 to 1 litre (i.e., by $83 \%$ ).

\section{Materials and Methods}

\section{Study design and population}

The null hypothesis was that an evidence-based skin care intervention which added $2 \%$ glycerine to the current skin regimen used to treat Ethiopian podoconiosis patients would not improve SBF and disease-related quality of life, compared to the current regimen. The study used an RCT parallel-group design. Data were collected from two APIDO clinics in the 
Gamo Gofa zone, Southern Ethiopia, January-August 2014. Clinics were chosen within similar socio-economic populations and geographical areas (with volcanic soil, high rainfall and elevations $>1600$ meters above sea-level). Inclusion criteria were previously untreated patients with podoconiosis (determined by the experienced clinic nurses), over 18 years able to give informed consent.

\section{Sample size and selection}

Computerised stratification of the sample ensured similar gender numbers and those with mild/moderate (Stages 1-3) to severe disease (Stages 4-5) ${ }^{7}$; this allowed variance between these factors to be determined. The study was powered to detect a difference between the treatment groups. Based on the pilot study results ${ }^{19}$, an effect size of around 0.72 was expected for TEWL (primary outcome measure). To achieve a power of $80 \%$ (2-sided t-test) with a 5\% significance level, 64 participants were required, divided equally between the two treatment groups. To allow detection of possible smaller effect sizes on other secondary outcome measures, a target sample size of 200 was chosen. Participants were allocated randomly to groups using a computer-generated sequential system based on clinic, gender and disease severity. Randomisation was explained to participants as their allocation to a group using the current effective treatment or another using an extra harmless product. Four containers were placed in each clinic (labelled by gender/disease severity) containing individually-coded sealed opaque envelopes opened sequentially by the nurse to reveal group allocation.

\section{Ethical approval}

Ethical approval for the study was obtained from the University of Hull, UK (Approval letter reference 125, 29.11.13) and Sodo University, Ethiopia (24/214/2013). An explanation of the study was read out by the clinic nurse to each potential participant and any clarifying questions answered. As most were illiterate, those willing to take part signed or marked their agreement with a cross or ink mark from their index finger, witnessed, signed and dated by the clinic social worker.

\section{Study groups and Intervention tested}

Each individual was taught (verbally and by demonstration) initially and at each monthly visit how to treat their feet/legs according to their group. Control group subjects continued 
with the daily skin treatment used currently in APIDO clinics (see Introduction). In the experimental group:

- 1 litre of water (only) was used for feet soaking and splashing lower legs.

- $20 \mathrm{ml}$ glycerine was added to provide a $2 \%(\mathrm{v} / \mathrm{v})$ dilution.

\section{Measures used}

Primary outcome measures of TEWL and SCH were measured using portable, wireless, noninvasive probes (Delfin Technologies Ltd., Finland). TEWL (water flux across the SC, measured in grams of water per square meter, per hour) was measured with a VapoMeter ${ }^{\circledR}$ closed-chamber evaporimeter and SCH (reflecting SC water content) was measured in arbitrary units using a MoistureMeter $\mathrm{SC}^{\circledR}$ probe (based on electrical capacitance). These instruments were used previously by one of the authors (PM) to successfully measure SBF in those with podoconiosis in rural Ethiopia ${ }^{4}$. Measurements were taken at three sites - on the outer, lower leg ( $8 \mathrm{~cm}$ below the fibula head (top), $8 \mathrm{~cm}$ above the external malleolus (base) at mid-point between these sites and the top of the foot (similar to Ferguson $e t$ al. ${ }^{4}$ ).

In each site, SCH measures were made in triplicate (recording the mean). Single TEWL measures were recorded. With both of these objective instrumental measurements, it is critical to minimise interference from environmental artefacts. In line with the manufacturer's ${ }^{20}$ and other published guidelines ${ }^{21}$, therefore, measurements were restricted to times of the day when ambient temperature was lower, and patients asked to rest and equilibrate for at least 20 minutes, with measurement sites exposed. This process was aided by the automatic recording of ambient temperature and humidity by the VapoMeter $^{\circledR}$. Measurements of TEWL are particularly challenging in external environments. The use of a closed-chamber evaporimeter proved to be critical in reducing local atmospheric perturbation and resulting measurement noise (as per Ferguson et $a l .{ }^{4}$ ).

Other measures recorded were: stage of podoconiosis, trophic changes (mossy/papillomatosis changes present/absent), malodour (if detected on foot/leg by clinic nurse), number of wounds, work days lost due to ADL (defined as an episode of inflammatory pain associated with the lymph nodes within a lymphoedematous leg which led patients to be bedridden/unable to work), largest leg and foot circumferences. The Amharic Dermatology Life Quality Index (ADLQI) was used which has been validated for use in those with 
podoconiosis $^{22}$. The ten questions assess aspects of an individual's disease-related quality of life. The maximum score of 3 for each question indicates that the disease has a high impact, 2 a lot of impact, 1 a little and 0 none or the question is irrelevant.

\section{Data collection}

The qualified nurses and social workers who had worked at each clinic for at least 1 year received an initial 5 hour standardised training session provided by the Principal Investigator (PI). This included practising measuring the liquids used in the trial, using the instruments and completing the data forms under PI supervision. Due to high rates of illiteracy, ADLQI questions were read out to individual participants by the clinic nurse.

A local nurse (with a Masters Degree in Public Health, studying podoconiosis, visited each clinic to monitor and review data collection and participant treatment at least seven times across the 7 month trial period. The PI also directly monitored staff at each clinic, their teaching of participants and data collection at weeks 1 (each day for 5 days) and then at weeks, 10, 17, and 24.

Baseline data were collected prior to intervention (Visit 1) and data were then collected monthly for three months (Visits 2-4).

\section{Data Analysis}

The data analytic plan was developed a priori. Data were entered into SPSS 22.0 (SPSS Inc., Chicago, IL., USA) a statistical package and checked for outliers and completeness prior to analysis. Mixed multi-level modelling was used for continuous outcome measures. For each such measure, the change from baseline at Visits 2-4 was calculated and used as the dependent variable in the analytic model. Generalised estimating equations (GEES) were used for discrete, categorical or binary outcome measures. For each such measure, the change from baseline at Visits 2-4 was calculated and used as the dependent variable in the model. The variables controlled for each outcome measure model were group, clinic, gender, initial stage of podoconiosis (Visit 1), side (right/left) of leg and the value of corresponding measures at Visit 1. A group-by-time interaction was included in the model to allow the group difference, if any, to vary in time. 


\section{Results}

193 participants enrolled onto the study; (97 in the control group and 96 in the experimental group. All completed except one male control group patient with mild/moderate disease who did not attend Visit 4. Details are in the Consort Flow Chart (Figure 2). All legs with clinical signs of podoconiosis were used as the unit for analysis $(n=383)$. Three participants $(1.5 \%)$ had only one of their legs/feet with clinical signs of podoconiosis. Twenty five participants (12.9\%) had different stages of podoconiosis in each of their legs, (moderate/less severe versus severe). No adverse treatment effects were noted.

\section{Profile of participants at baseline}

Table 1 provides a demographic profile of patients at baseline.

\section{Trans-Epidermal Water Loss}

Baseline mean TEWL values in both groups were greatest on the top of feet (weaker SBF) and decreased progressively up the lower leg (indicating stronger SBF; Table 2). Mean TEWL values in lower legs/feet sites reduced in both groups at Visits 2-4, although the reduction was greater in the experimental group (highly significant group difference for all legs/feet sites at Visit 4), (Table 3, Figure 3). At all points at Visits 2-4 TEWL reduction was greater in right legs and highly statistically significant. At the top of the lower leg the difference was $(\mathrm{t}=-3.415, \mathrm{df}=186.089, \mathrm{p}=0.001,95 \% \mathrm{CI}=(-0.574$ to-0.154)), at mid-point $(\mathrm{t}=-$ 2.588, $\mathrm{df}=187.075, \mathrm{p}=0.010,95 \% \mathrm{CI}=-0.645$ to -0.087$)$, at base $(\mathrm{t}=-2.616, \mathrm{df}=189.834$, $\mathrm{p}=0.010,95 \% \mathrm{CI}=-0.595$ to 0.083$)$ and on the foot $(\mathrm{t}=-2.570, \mathrm{df}=189.489, \mathrm{p}=0.011,95 \%$ $\mathrm{CI}=-0.625$ to- 0.082 ) .

\section{Stratum corneum hydration}

Baseline mean SCH was lower at the base of the leg and top of the feet increasing progressively up the lower leg (Table 4). Mean SCH values at all points on the lower legs/feet increased in both groups over Visits 2-4, although the increase was greater in the experimental group (highly significant), (Table 5, Figure 4).There was no significant difference in $\mathrm{SCH}$ between right and left legs except at the base of the lower leg (nearing significance $)(\mathrm{t}=1.916, \mathrm{df}=180.987, \mathrm{p}=0.057,95 \% \mathrm{CI}(-0.654$ to 0.010$))$. 


\section{Stage of podoconiosis}

At baseline, 176 legs (45.5\%) displayed severe disease (Stages 4-5). By Visit 4, this number had decreased to 50 legs (10.6\%). Similarly, at baseline, 227 legs (54.5\%) displayed mild/moderate disease (Stages 1-3). By Visit 4, this number had increased to 320 legs (89.3$5 \%$ ). Together, these results indicate clinical improvement due to the two treatment regimens based on the description of stages. There was no significant treatment group difference at Visit 4 (Log odds ratio=0.452, $(\mathrm{SE}=0.255)$, Wald chi square $=3.138, \mathrm{df}=1, \mathrm{p}=0.076,95 \% \mathrm{CI}(-$ 0.048 to 0.952$)$ ) nor stage difference between right/left legs.

\section{Trophic ("Mossy") skin changes}

At baseline, trophic skin changes were present in 153 (79.3\%) right legs/feet and in 156 $(80.8 \%)$ left legs/feet. By Visit 4, trophic changes were reduced and present in $120(62.5 \%)$ right legs/feet and 117 (60.9\%) left legs/feet: however, there was neither a significant treatment group difference at Visit 4 nor between right/left legs.

\section{Odour}

At baseline, odour was present in 114 (59.1\%) of legs/feet. By Visit 4, odour was reduced and present in only 2 right legs/feet (1\%) and 1 left leg/foot $(0.5 \%)$. The odds of leg odour being present at Visits 2,3 and 4 was significantly less in the experimental group (Log odds ratio $=-0.866,(\mathrm{SE}=0.401)$, Wald chi square $=4.67, \mathrm{df}=1, \mathrm{p}=0.031,95 \% \mathrm{CI}(-1.652$ to -0.080$))$. However, the group difference was not clinically significant because the numbers with leg odour in each group reduced to almost zero.

\section{Number of wounds}

At baseline, 105 (54.4\% of participants had 4 wounds (all skin breaches and all areas of fungal infection on the legs/feet). The experimental treatment led to significantly fewer wounds present on legs/feet at Visits 2-4 (significant $(\mathrm{p}<0.05)$ group difference). Those in the experimental group were expected to have fewer wounds (group ratio estimate $=2.062$ $(\mathrm{SE}=0.741)$, Wald chi-square $=7.745, \mathrm{df}=1, \mathrm{p}=0.005,95 \% \mathrm{CI}(0.610$ to 3.514$))$. As most participants at the fourth visit had no wounds, the group difference was clinically insignificant. 


\section{Number of days of work lost in previous month due to adenolymphangitis (ADL)}

At baseline, the mean number of work days lost in the previous month due to ADL was 4.56 for the control group and 4.44 for the experimental group. The group ratio in the expected number of days lost at Visit 4 was not significant (group ratio estimate=2.090, (SE=1.102), $\mathrm{df}=1, \mathrm{p}=0.058,95 \% \mathrm{CI}(-0.069$ to 4.250$))$; neither was the difference clinically significant as no participants lost any work days in the previous month due to ADL.

\section{Correlation between days lost due to adenolymphangitis and number of wounds}

A Spearman's correlation at baseline was 0.252 , at the second visit 0.306 , the third 0.291 and the fourth 0.265 . This indicated that at all time points there was a weak although highly significant correlation $(\mathrm{p}=<0.001)$ between the number of lower leg/foot wounds totalled over both legs and the number of days participants were unable to work due to ADL for Visits 2, 3 and 4.

\section{Largest lower leg circumference}

In the control group the largest lower leg circumference reduced over the study period by $3.8 \mathrm{~cm}(32.1 \mathrm{~cm}$ to $28.3 \mathrm{~cm})$ and in the experimental group by $4.2 \mathrm{~cm}(32.0 \mathrm{~cm}$ to $27.8 \mathrm{~cm})$. The between group treatment difference was not significant $(\mathrm{t}=1.416, \mathrm{df}=185.386, \mathrm{p}=0.158,95 \%$ CI (-0.113 to 0.690$)$.

\section{Largest foot circumference}

In the control group, the mean foot circumference reduced over the study period by $2.4 \mathrm{~cm}$ $(27.5 \mathrm{~cm}$ to $25.1 \mathrm{~cm})$. The reduction was greater in the experimental group (by $3 \mathrm{~cm}(27.7 \mathrm{~cm}$ to $24.7 \mathrm{~cm})$. The treatment group difference was highly statistically significant $(\mathrm{t}=3.550$, $\mathrm{df}=169.916, \mathrm{p}=<0.001,95 \% \mathrm{CI}(0.255$ to 0.895$)$. The reduction in circumference was greater in the right foot (highly significant) $(\mathrm{t}=-3.270, \mathrm{df}=152.994, \mathrm{p}=0.001,95 \% \mathrm{CI}(-0.239$ to 0.059)).

\section{Amharic Dermatology Life Quality Index (ADLQI)}

The mean ADLQI reduced in both groups over the study period indicating an improved selfassessed disease-related quality of life. In the control group, the mean ADLQI reduced from 
21.6 to 4.1 (an improvement of 17.5 points). In the experimental group, the mean ADLQI reduced from 21.1 to 3.9 (an improvement of 17.2 points). The estimated group difference at Visit 4 was not statistically significant $(\mathrm{t}=-0.117, \mathrm{df}=178.814, \mathrm{p}=0.907,95 \% \mathrm{CI}(-1.129$ to 1.002)).

\section{Discussion}

To our knowledge, this is the first RCT to study podoconiosis skin care regimens and the largest to use a dilution of only $2 \%$ glycerine to improve SBF. As hypothesised, the addition of $2 \%$ glycerine (v/v) to a significantly lower volume of soaking water led to significant incremental improvements in SBF in the lower legs and feet of those with podoconiosis. This was evident in significantly higher recorded values of SCH and lower recorded values of TEWL in skin on the legs and feet of those receiving the experimental versus the current treatment regime. This was accompanied by significantly greater reductions in malodour, number of wounds and largest circumference of foot in the experimental group compared to the control group. No adverse effects were reported.

Ferguson et al. ${ }^{4}$ measured SBF in those with podoconiosis versus matched control subjects in a previous non-intervention study. They reported significantly lower levels of SCH in the feet/lower legs of those with podoconiosis, indicating a greater propensity to SC dryness and cracking for those with the disease (hence, a higher risk of reactive soil/pathogens entering foot tissue). This current study builds upon these insights and demonstrates conclusively the central role of compromised SBF in the induction and propagation of podoconiosis. There is no other explanation for the relatively acute significant effect of only $2 \%$ glycerine $(\mathrm{v} / \mathrm{v})$ in a simple water soak on both objective SBF measures and clinical outcome in this chronic lymphoedematous condition.

We propose a therapeutic model centred around increasing SC hygroscopicity and the cascade of ensuing events summarised by Rawlings and Matts ${ }^{23}$, including; i) an immediate reduction in the SC elastic modulus, resulting in a softer, more flexible substrate less prone to cracking/splitting; ii) longevity of $\mathrm{SCH}$, activating desquamatory enzymes in previously dry $\mathrm{SC}$, leading to a significantly thinner, more compact SC over time; iii) a reduction in inflammatory process, leading to a more mature, efficient SC and iv) ultimately, restoration of healthy SBF, better able to prevent ingress of irritant soil/pathogens into tissue. 
Sikorski et al. ${ }^{14}$ investigated the effect of a similar skin hygiene regimen in podoconiosis patients vs a control group over 1 year. Despite this current study being only 3 months in length, we report higher reductions in largest lower leg circumference $(-4.0 \mathrm{~cm}$ and $-4.1 \mathrm{~cm}$ in this study vs $2.0 \mathrm{~cm}$ for Sikorski et al. $\left.{ }^{14}\right)$ and a greater improvement in ADLQI score (17.1 and 17.5 points in this study vs 15.0 Sikorski et al. $\left.{ }^{14}\right)$. We cannot account for this difference in response but hypothesise that this may be due to different study populations, locations, climate or skin regimen compliance.

In this current 3 month intervention study, $62.7 \%$ of legs/feet still had "mossy" trophic changes evident across the treatment groups, compared to $22.2 \%$ reported by Sikorski et al, after a year of treatment ${ }^{14}$. This indicates that a longer period of continuous treatment is probably needed to reduce trophic changes. It is remarkable that an intervention comprising water, soap and petrolatum can bring about these improvements at all and, once again, indicates the importance of improving and maintaining SBF in the treatment regimen.

In this study, a reduction in the number of wounds in both groups was associated with a reduction in the work days lost due to ADL. This is important, as most of those in this study were subsistence farmers, so any income loss would have significant economic effects. Indeed, it is estimated that Ethiopia loses approximately 200 million USD annually through lost work days due to podoconiosis ${ }^{10}$.

This current study and Sikorski et als. ${ }^{14}$ both demonstrate the utility of simple treatment regimes in significantly improving quality of life in those with podoconiosis (evidenced by improved DLQI scores). We hypothesise that this is likely due to a combination of the skin care and attention received in treatment sites, the visible improvement in leg/foot condition, a reduction in ADL and odour and a concomitant decrease in stigma and ostracism.

The significant difference in TEWL reduction in right legs compared to left legs and greater reduction in circumference of the right foot may have been due to more attention being given to the right leg during treatment or to this leg being used more than the left when walking (in those with a right side preference). Exercise is known to improve circulation and venous return thus reducing oedema ${ }^{6}$. It may also have been explained by the anatomical and 
physiological differences between legs which impair left leg venous and lymphatic drainage ${ }^{25}$.

Finally, in this study, we incorporated $2.0 \%$ glycerine (v/v) into only 1 litre of wash/soaking water (versus current 6 litres). Participants were able to follow instructions and use the new treatment protocol effectively. This new regimen not only conserves the precious resource of water, but also minimises the glycerine requirement.

In summary, the results of this study support our hypothesis that current podoconiosis treatment regimens can be enhanced further by increasing the water-binding potential of the SC with the humectant, glycerine. This is widely available in Ethiopia, even in rural settings, at low cost. The addition of glycerine to a water soak may be effective in a wide variety of other skin diseases, including lymphoedematous conditions such as lymphatic filariasis, where compromised SBF is indicated and skin care is critical. Glycerine use in podoconiosis treatment is currently being considered for implementation by APIDO. Further research is needed to investigate lower dilutions of glycerine and different soaking methods (e.g., wrapping technique), to further reduce cost, water usage and increase efficiency.

\section{Study limitations}

Podoconiosis diagnosis was based on participants living at high altitude, with volcanic soil, high rainfall, displaying clinical manifestations of the disease. No differential diagnosis was made to exclude those with swelling of the lower leg due to other diseases such as lymphatic filariasis, liver or heart failure. Although groups were matched as far as possible, there may have been other confounding factors influencing the results that are not identified. Although participants were not supervised daily to ensure treatment adherence, improvements in SBF would not have been achieved without some level of compliance.

\section{Acknowledgments}

We would like to thank the participants and staff in the APIDO clinics, Zelalem Mathewos (APIDO General Manager), Anteneh Mengistu (data collection supervisor) and Procter and Gamble for independent financial support and the loan of the probes used in the study. 


\section{References}

(1) Molla YB, Le Blond JS, Wardrop N, Baxter P, Atkinson PM, Newport MJ, et al. Individual Correlates of Podoconiosis in Areas of Varying Endemicity: A Case-Control Study. PLoS Negl Trop Dis 2013 12;7(12):1-11.

(2) Price E W, Bailey D. Environmental factors in the etiology of endemic elephantiasis of the lower leg in tropical Africa. Trop. Geogr. Med 1984;36:1-5.

(3) Molla YB, Wardrop NA, Le Blond JS, Baxter P, Newport MJ, Atkinson PM, et al. Modelling environmental factors correlated with podoconiosis, a geospatial study of nonfilarial elephantiasis. International Journal of Health Geographics 2014 07;13(1):1-23.

(4) Ferguson JS, Yeshanehe W, Matts PJ, Davey G, Mortimer PS, Fuller LC. Assessment of Skin barrier function in Podoconiosis: Measurement of Stratum Corneum hydration and Trans Epidermal Water Loss. Br J Dermatol 2013;168(3):550-554.

(5) Vaqas B, Ryan T. Lymphovenous Canada: An Update on the Low Cost Management of Lymphoedema in the developing world www.lymphovenous-canada.ca/management.htm edn. 2001.

(6) Lymphoedema Framework. Best Practice for the Management of Lymphoedema. International consensus. www.woundsinternational.com/pdf/content edn. London: MEP Ltd. 2006.

(7) Tekola F, Ayele Z, Mariam DH, Fuller C, Davey G. Development and testing of a de novo clinical staging system for podoconiosis (endemic non-filarial elephantiasis). Trop Med Int Health 2008, 10;13(10):1277-1283.

(8) Addisu S, El-Metwally T, Davey G, Worku Y, Titheradge MA. The role of transforming growth factor- $\beta 1$ and oxidative stress in podoconiosis pathogenesis. Br J Dermatol 2010, 05;162(5):998-1003.

(9) Tekola A, F., Adeyemo A, Finan C, Hailu E, Sinnott P, Burlinson N,D., et al. HLA class II locus and susceptibility to podoconiosis. N Engl J Med 2012 03/29; 366(13):1200-1208. 
(10) Tekola, F., Mariam, D.H. and Davey, G., Economic costs of endemic non-filarial elephantiasis in Wolaita Zone, Ethiopia. Tropical Medicine \& International Health 2006, 11(7), pp. 1136-1144.

(11) Ayode D, Tora A, Farrell D, Tadele G, Davey G, McBride CM, Dual Perspectives On Stigma: Reports of Experienced and Enacted Stigma by Those Affected and Unaffected by Podoconiosis. Journal of Public Health Research 2016. 19; 5(2):689.

(12) Watanabe E, McBride CM, Tora A, Ayode DA, Farrell D, Davey G. Use of footwear and foot condition among rural Ethiopian school children. J Epidemiol Glob Health 2014;4(4):323-5.

(13) Draelos ZD. Active agents in common skin care products. Plast Reconstr Surg 2010 $02 ; 125(2): 719-724$.

(14) Sikorski C, Ashine M, Zeleke Z, Davey G. Effectiveness of a simple lymphoedema treatment regime in podoconiosis management in Southern Ethiopia: one year follow-up. Negl Trop Dis 2010. PLoS Negl Trop Dis (electronic resource) vol./is.4/11(e902)10352727;1935-2735).

(15) Fluhr JW, Darlenski R, Surber C. Glycerol and the skin: Holistic approach to its origin and functions. Br J Dermatol 2008;159(1):23-34.

(16) Atrux-Tallau N, Romagny C, Padois K, Denis A, Haftek M, Falson F, et al. Effects of glycerol on human skin damaged by acute sodium lauryl sulphate treatment. Arch Dermatol Res 2010. 08;302(6):435-441.

(17) Iiyama J, Kawahira K. Effects of bathing in warm water with added glycerin on skin conditions and prevention of skin disorders in patients with severe motor and intellectual disabilities. J Japan Soc Balneol Climatol Phys Med 2008 05;71(3):173-179.

(18) Fluhr JW, Cavallotti C, Berardesca E. Emollients, moisturizers, and keratolytic agents in psoriasis. Clin Dermatol 2008;26(4):380-386. 
(19) Brooks J, Cowdell F, Ersser SJ, Gardiner ED. Skin cleansing and emolliating for older people: A quasi-experimental pilot study, International Journal of Older People Nursing 12 January 2017 DOI: 10.1111/opn.12145.

(20) Delfin Technologies Ltd., 2013-last update. Available at: www.delfintech.com/.

(21) Berardesca E, EEMCO guidance for the assessment of stratum corneum hydration: electrical methods. Skin Research and Technology 1997, 3(2):126-32.

(22) Henok L and Davey G. Validation of the Dermatology Life Quality Index among patients with podoconiosis in Ethiopia British Journal of Dermatology 2008. 159 (4) pp 903$\underline{906 .}$

(23) Rawlings AV and Matts PJ. Stratum corneum moisturisation at the molecular level: an update in relation to the Dry Skin Cycle. J Invest Dermatol 2005;124:1099-1102.

(24) Deribe K, Wanji S, Shafi O, Tukahebwad EM, Umulisa I, Molyneux DH, Davey, G. The feasibility of eliminating podoconiosis. Bulletin of the World Health Organization 2015; 93:712-718.

(25) Schrale G and Ryan T. Managing Oedema and Fibrosis with Coordinated Movement. Journal of Lymphoedema 2011; 6(2), 82-86. 


\section{Figure legends}

Picture 1. Feet of patients presenting with oedema, hyperkeratosis, nodules, fused toes, mossy changes and ulceration due to ill-fitting shoes.

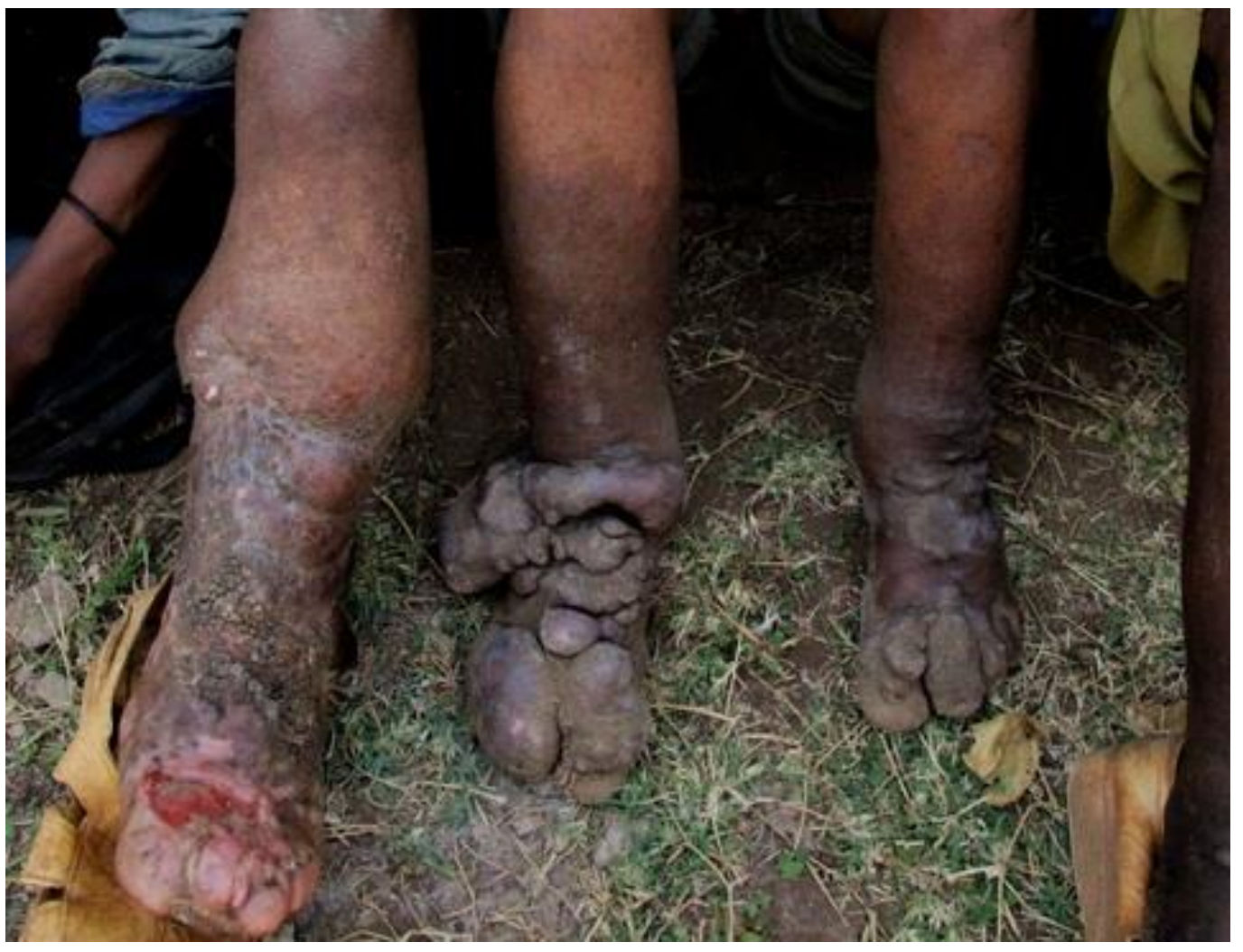


Figure 1. Development and cycle of progression of lymphoedema in podoconiosis.

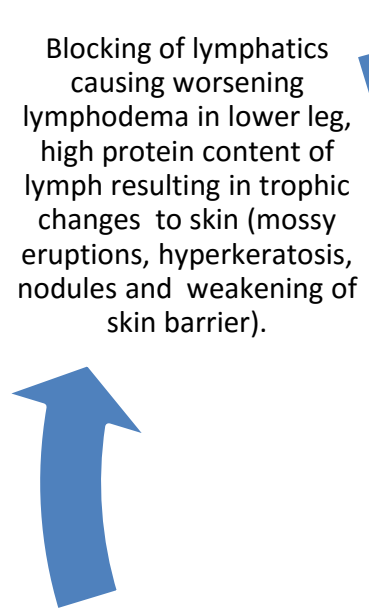

Skin swelling with damage to superficial lymphatics. Lymph distributed along upper dermal network instead of epidermal network resulting in lymphoedema, venous hypertension and further capillary leakage.

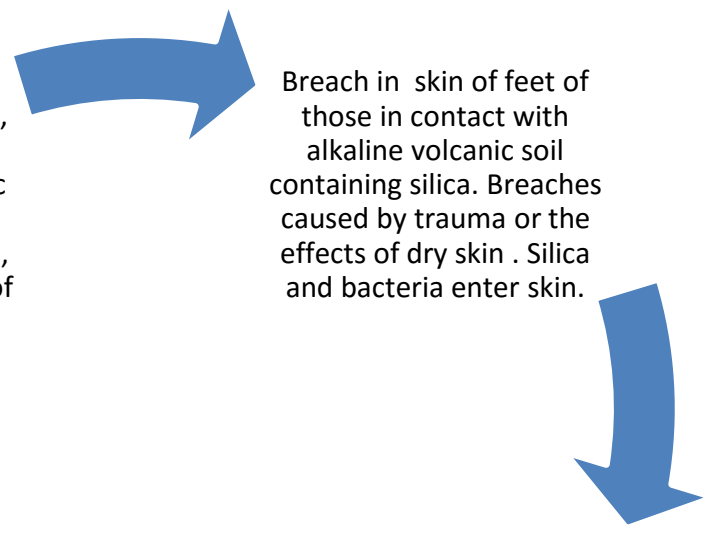

Subsequent inflammatory response with activation of macrophages, leucocytes and cytokines. Histamine produced by basophils and mast cells. This increases permeability of capillaries to white blood cells and some proteins, allowing them to engage with the pathogens. Bradykinin and prostacyclin cause blood vessels to dilate. 
Table 1. Demographic profile of all participants at baseline $(n=193)$

\begin{tabular}{|l|l|l|l|}
\hline Age (years) & Occupation & Time to onset (years) & Shoes worn in previous week \\
\hline $18-29,28 \%(54)$ & farmers, 46.1\% (89) & $>1$ year, 1\% (2) & barefoot, 9.4\% (18) \\
\hline $30-39,15.8 \%(33)$ & housewives, 42.5\% (82) & $1-2$ years, 24.4\% (47) & hard plastic sandals, 62.2\% (120) \\
\hline $40-49,22.5 \%(47)$ & students, 7.3\% (14) & $3-4$ years, 25.4\% (49) & canvas shoes, 12.4\% (24) \\
\hline $50-59,15.3 \%(32)$ & $\begin{array}{l}\text { others, 4.1\% (8) e.g. } \\
\text { servants and merchants }\end{array}$ & $5-6$ years, 24.4\%, (47) & other enclosed shoes,10.4\% (20) \\
\hline $60-69,22(10.5 \%)$ & & $7-8$ years, 11.9\% (23) & open sandals made with tyres, 4.7\% (9) \\
\hline$>70,2.6 \%(5)$ & & $9-10$ years 9.3\% (18) & other sandals, 1\% (2) \\
\hline & & $11-12$ years.2.1\% (4) & \\
\hline & & $>12$ years 1.6\% (3) & \\
\hline
\end{tabular}


Table 2. Mean TEWL ( $\left.\mathrm{gm}^{2} \mathrm{~h}\right)$ across all participants measured at different anatomical sites within podoconiosis-affected legs/feet, at baseline.

\begin{tabular}{|l|l|l|}
\hline Site on the lower leg & $\begin{array}{l}\text { Mean TEWL }\left(\mathbf{g m}^{2} \mathbf{h}\right) \text { right leg } \\
\mathbf{1}^{\text {st }} \text { Visit }\end{array}$ & $\begin{array}{l}\text { Mean TEWL }\left(\mathbf{g m}^{2} \mathbf{h}\right) \text { left leg } \\
\mathbf{1}^{\text {st }} \text { Visit }\end{array}$ \\
\hline Top & 13.08 & 13.40 \\
\hline Mid-point & 14.29 & 15.02 \\
\hline Base & 16.62 & 17.17 \\
\hline Top of Foot & 22.41 & 22.75 \\
\hline
\end{tabular}


Table 3. TEWL $\left(\mathrm{gm}^{2} \mathrm{~h}\right)$ - estimated group differences at Visits 2, 3, 4.

\begin{tabular}{|l|l|l|l|l|l|l|}
\hline $\begin{array}{l}\text { Anatomical } \\
\text { site }\end{array}$ & $\begin{array}{l}\text { Estimated } \\
\text { group } \\
\text { difference } \\
\left(\mathbf{g m}^{2} \mathbf{h}\right)\end{array}$ & $\begin{array}{l}\text { Standard } \\
\text { Error }\end{array}$ & $\mathbf{t}$ & $\mathbf{d f}$ & $\mathbf{p}$ & $\begin{array}{l}\text { 95\% CI for the } \\
\text { group difference }\end{array}$ \\
\hline $\begin{array}{l}\text { Top of outer } \\
\text { lower leg }\end{array}$ & 1.582 & 0.296 & 5.341 & 89.347 & $<0.001$ & $(0.997,2.164)$ \\
\hline $\begin{array}{l}\text { Mid-point of } \\
\text { outer lower leg }\end{array}$ & 1.684 & 0.346 & 4.871 & 189.789 & $<0.001$ & $(1.0023,2.367)$ \\
\hline $\begin{array}{l}\text { Base of outer } \\
\text { lower leg }\end{array}$ & 1.970 & 0.386 & 5.111 & 189.620 & $<0.001$ & $(1.210,2.731)$ \\
\hline $\begin{array}{l}\text { Middle of top of } \\
\text { foot }\end{array}$ & 1.751 & 0.390 & 3.154 & 189.580 & 0.002 & $(0.656,2.846)$ \\
\hline
\end{tabular}


Figure 2. CONSORT 2010 Flow Diagram

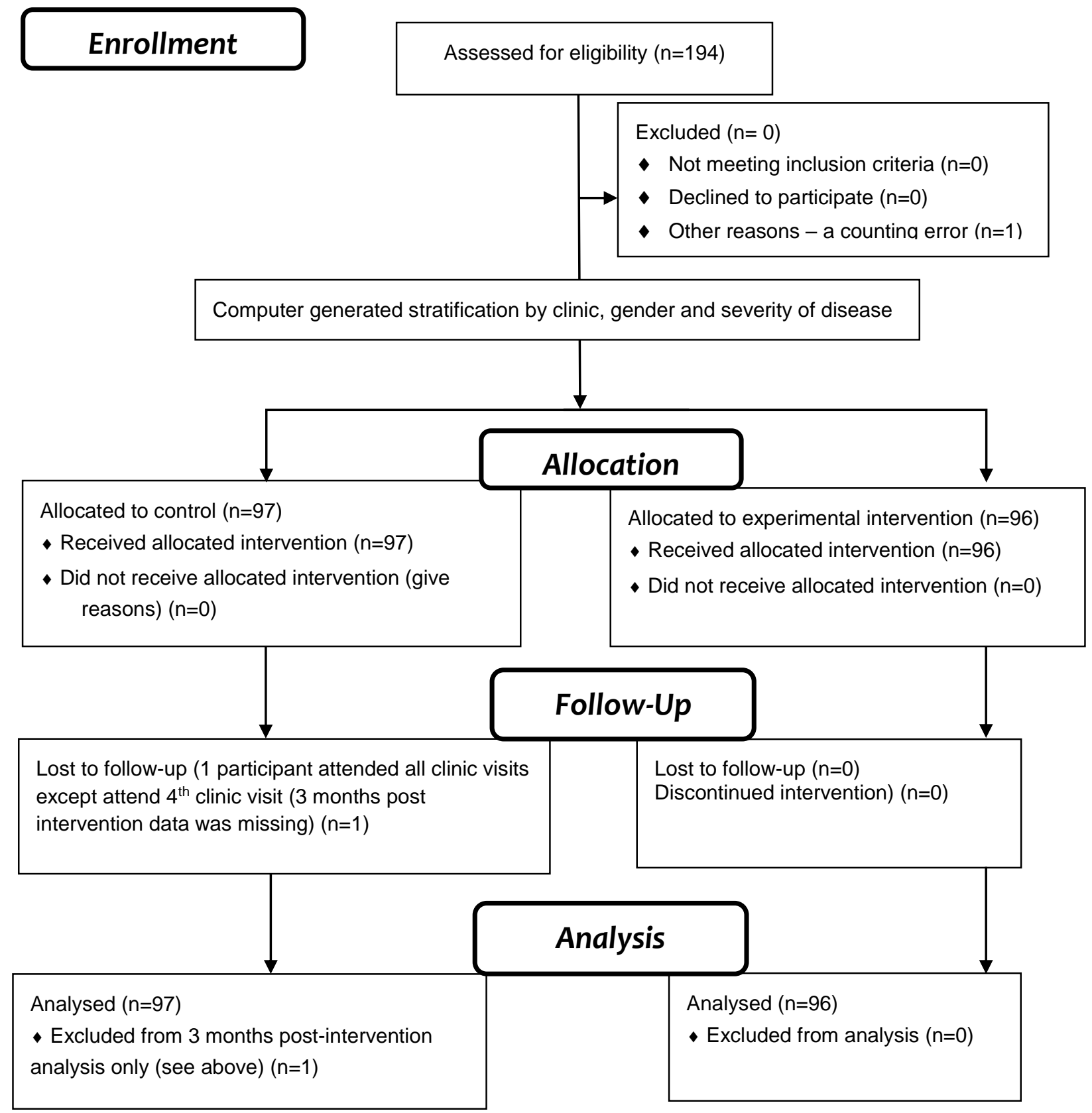


Figure 3. Top of foot - difference over time between groups in mean TEWL $\left(\mathrm{gm}^{2} \mathrm{~h}\right)$

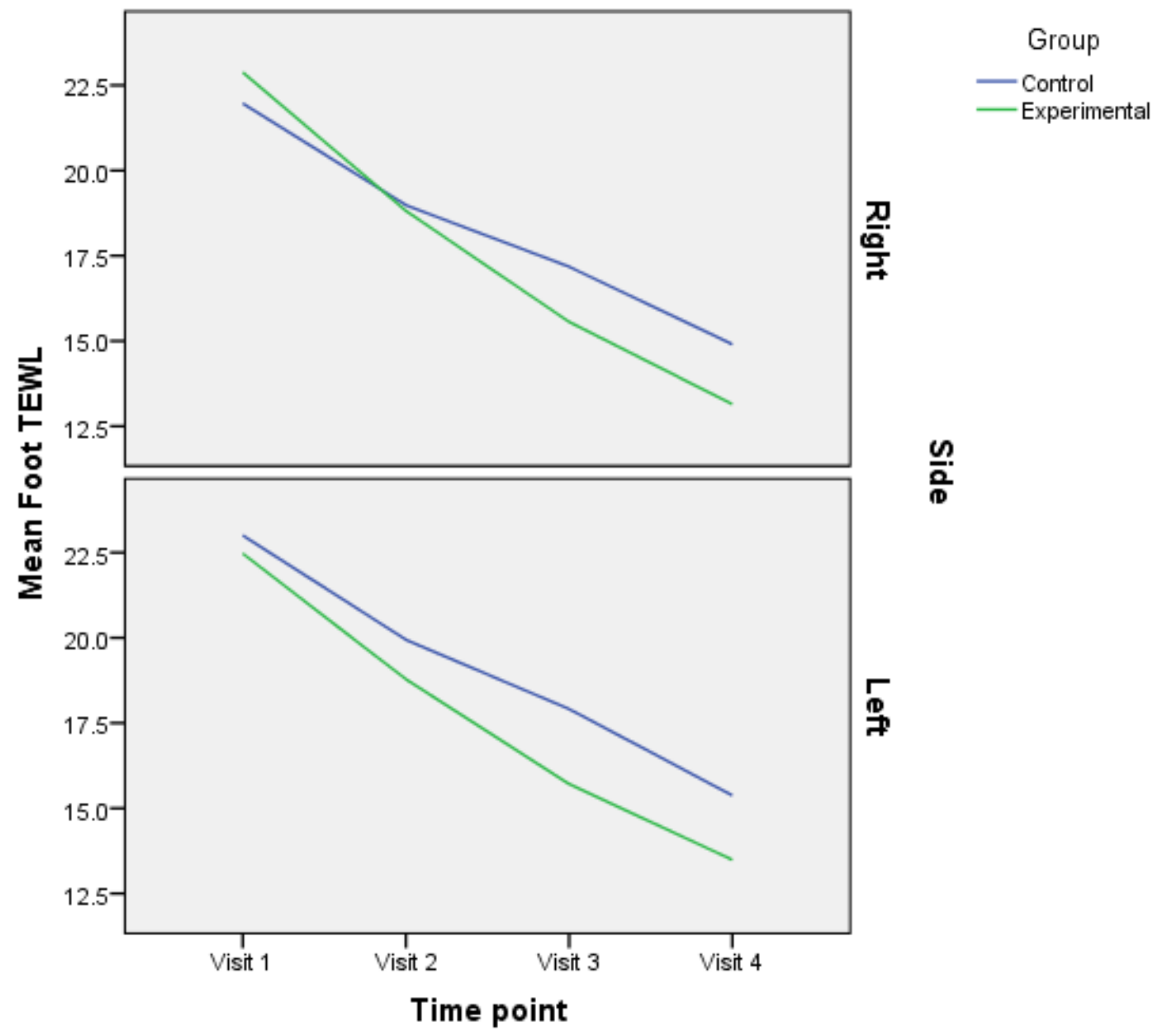


Table 4. Mean SC hydration (Moisture Meter SC; AU) (arbitrary units) across all participants measured at different anatomical sites within podoconiosis affected legs/feet at baseline

\begin{tabular}{|l|l|l|}
\hline Point on the lower leg & Mean SC hydration right lower leg & Mean SC hydration left lower leg \\
\hline Top & 9.33 & 9.54 \\
\hline Mid-point & 9.03 & 9.23 \\
\hline Base & 8.51 & 8.55 \\
\hline Top of foot & 8.49 & 8.62 \\
\hline
\end{tabular}


Table 5. SC hydration (arbitrary units) - estimated group differences at Visits 2, 3 and 4

\begin{tabular}{|l|l|l|l|l|l|l|}
\hline $\begin{array}{l}\text { Anatomical } \\
\text { site }\end{array}$ & $\begin{array}{l}\text { Estimated } \\
\text { group } \\
\text { difference }\end{array}$ & $\begin{array}{l}\text { Standard } \\
\text { Error }\end{array}$ & T & df & $\mathbf{p}$ & $\begin{array}{l}\text { 95\% CI for the group } \\
\text { difference }\end{array}$ \\
\hline $\begin{array}{l}\text { Top of lower } \\
\text { outer leg }\end{array}$ & -2.075 & 0.515 & -4.236 & 165.310 & $<0.001$ & $(-3.042,-1.108)$ \\
\hline $\begin{array}{l}\text { Mid-point lower } \\
\text { outer leg }\end{array}$ & -1.658 & 0.467 & 3.549 & 180.923 & $<0.001$ & $(-2.581,-0.736)$ \\
\hline $\begin{array}{l}\text { Base lower outer } \\
\text { leg }\end{array}$ & -1.641 & 0.473 & -3.471 & 186.308 & 0.001 & $(-2.574,-0.708)$ \\
\hline \begin{tabular}{l} 
Top of foot \\
\hline
\end{tabular} & -2.041 & 0.572 & -3.565 & 186.739 & $<0.001$ & $(-3.168,-0.911)$ \\
\hline
\end{tabular}


Figure 4. Top of foot - difference over time between groups in mean SC hydration (arbitrary units)

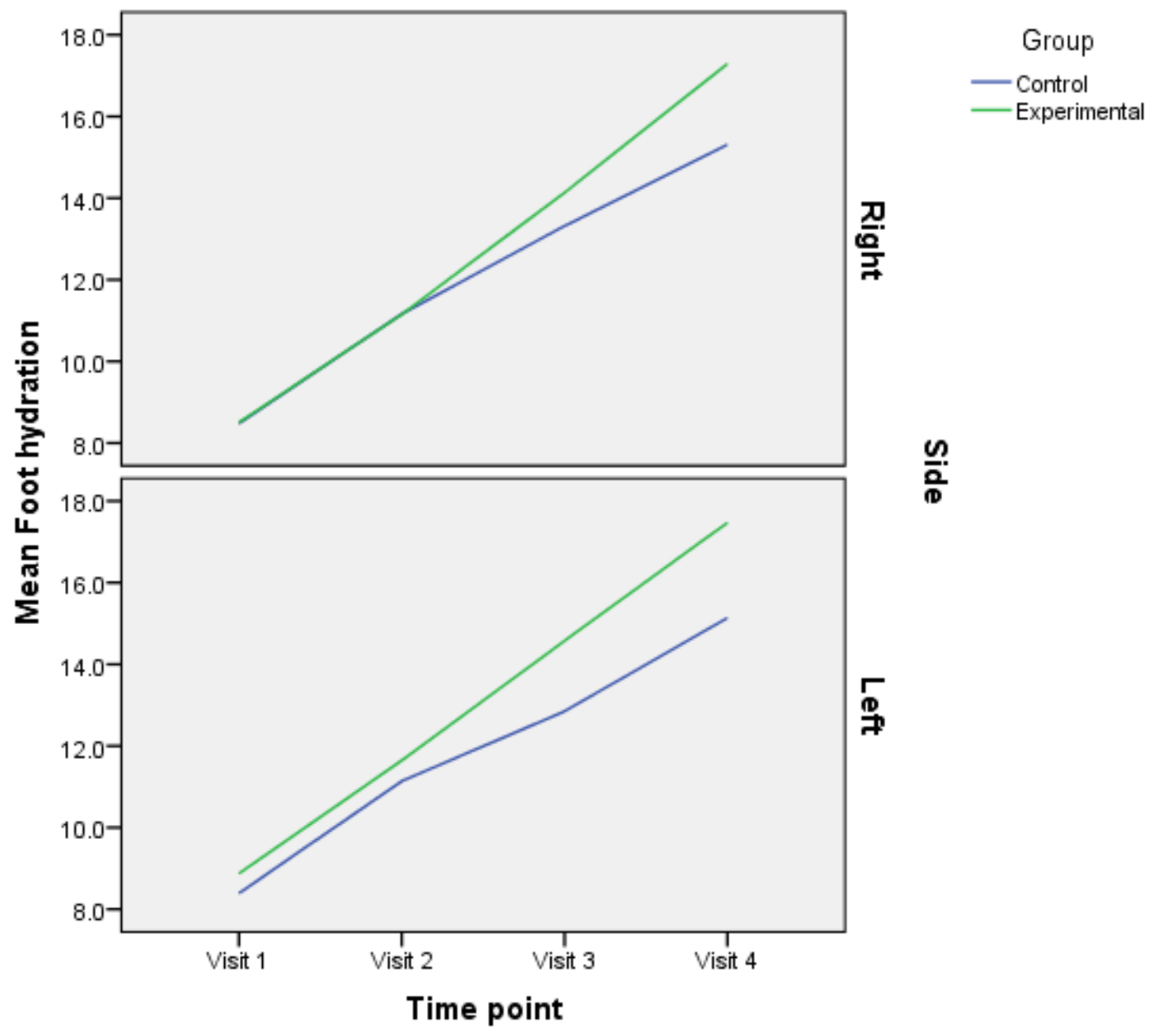

